TESIS DE LICENCIATURA

\title{
LA FORMACIÓN PARA EL TRABAJO EN UNA ESCUELA TÉCNICA NOCTURNA DE LA LOCALIDAD DE MACHAGAI, PROVINCIA DEL CHACO. LA PERSPECTIVA DE LOS JÓVENES, DE LA INSTITUCIÓN EDUCATIVA Y DEL SECTOR LABORAL ${ }^{1}$
}

\author{
Melisa Anabel Florez ${ }^{2}$
}

En la presente reseña se intenta exponer brevemente la investigación realizada en el marco del trabajo de tesis de Licenciatura en Ciencias de la Educación de la Facultad de Humanidades (UNNE). La temática se enmarcó en los estudios que abordan la compleja trama de la relación entre educación y trabajo y, dentro de ello, como las trayectorias socioeducativas y laborales de los jóvenes estudiantes adquieren ciertas características particulares; a la vez que asumen su transición a la vida adulta.

Interesa específicamente lo relacionado a los sentidos que los estudiantes construyen y adquieren sobre la formación, los cuales se configuran en función de sus trayectorias, determinadas por el contexto familiar, social y económico en el que se insertan y, por sus expectativas futuras. Construcción de sentidos, en la que también son relevantes otros actores intervinientes. De esta manera, se considera importante entender al sujeto joven desde una perspectiva biográfica, como un actor social, en un contexto histórico y geopolítico determinado, y donde su trayectoria vital se va articulando de forma compleja entre sus propias decisiones y las determinaciones externas.

En este marco, el estudio aborda la problemática de los sentidos que construyen diversos actores respecto a los procesos y resultados de la formación que se brinda en una escuela técnica, en este caso de orientación Madera y Mueble que funciona en el turno nocturno, y que se encuentra emplazada en un contexto regional específico, en la localidad de Machagai de la Provincia del Chaco.

Se asume que el trayecto educativo ofrece un cúmulo de conocimientos, saberes y herramientas a los jóvenes, para su desenvolvimiento en el ámbito laboral y social. En esas trayectorias, los actores inmersos en la institución y en un determinado contexto socio-productivo, cumplen un papel activo a través de sus discursos y prácticas para contribuir a la reconfiguración y significación de la escuela (como dispositivo de acompañamiento y formación para el trabajo), a nivel microsocial e institucional.

A partir de lo expuesto, el problema de la investigación se delimita en torno a qué sentidos se construyen -desde diversos actores- acerca de la formación para el trabajo de jóvenes estudiantes que asisten a una escuela técnica nocturna en la localidad del Machagai (Provincia del Chaco).

\footnotetext{
${ }^{1}$ Tesis para aspirar al grado académico de Licenciada en Ciencias de la Educación, Facultad de Humanidades, Universidad Nacional del Nordeste (68 págs.). Director Lic. Federico Butti. Defensa el 11 de diciembre de 2019.

${ }^{2}$ Prof. y Lic. en Ciencias de la Educación. Facultad de Humanidades, Universidad Nacional del Nordeste (UNNE). Resistencia, Chaco-República Argentina. Correo electrónico: anameli.florez@gmail.com
} 
El objetivo general propuesto para orientar la investigación es el de caracterizar y comparar los sentidos que construyen acerca de la formación para el trabajo jóvenes estudiantes, docentes y directivo de una escuela técnica nocturna (de orientación Madera y Mueble) y los representantes del sector de producción Foresto Industrial de la Madera en la localidad de Machagai, Provincia del Chaco.

La tesis está organizada en diferentes secciones donde se van exponiendo sistemáticamente los marcos teóricos y referenciales, las decisiones metodológicas adoptadas en el proceso, los resultados obtenidos y las conclusiones alcanzadas.

Respecto al marco referencial, las perspectivas teóricas se organizan en tres grandes ejes: a) Relación/vínculo Educación y Trabajo, b) Juventud como categoría/construcción social, y c) Trayectorias sociales y educativas.

Las decisiones metodológicas adoptadas para el trabajo de campo, estuvieron orientadas a la elección de un enfoque de tipo mixto (con componentes cualitativo y cuantitativo). Se realizó un análisis de datos secundarios -provenientes de documentos y normativas- y de datos primarios obtenidos de la aplicación de entrevistas y cuestionarios semiestructurados.

La población en estudio se constituyó por actores instituciones de la escuela y por actores representantes del sector de producción de la localidad. Esta delimitación respondió a que los sentidos y expectativas acerca de la formación para el trabajo, no solo están dados por los jóvenes estudiantes, sino también por otros actores que intervienen en esa articulación entre educación y trabajo. En este caso, producidos por docentes y directivo-como representantes de la institución educativa-y por los dueños de carpinterías y aserraderos-referentes de la comunidad vinculados al sector de producción. De este modo, la unidad de análisis quedó conformada por: estudiantes del $5^{\circ}$ y $6^{\circ}$ año de la orientación Madera y Mueble (seleccionando una muestra de 24 estudiantes), docentes (5 docentes de asignaturas: electricidad, CNC Y CAD CAM, dibujo técnico, de enseñanzas prácticas, jefe de taller y regente) y un directivo. Así como representantes del sector de producción Foresto Industrial de la Madera (3 empleadores de pequeñas y 3 de medianas empresas).

En cuanto a los resultados obtenidos en la investigación, se organizaron en dos apartados, el primero recupera la perspectiva que adoptan los docentes y director de la escuela técnica, junto a los empleadores de pequeñas y medianas empresas, acerca de la formación para el trabajo en los jóvenes. El segundo, caracteriza la perspectiva que construyen los jóvenes estudiantes, y los sentidos que otorgan a sus experiencias educativas, laborales y expectativas a futuro.

Desde una mirada institucional los sentidos se construyen en relación con la formación que se brinda en la escuela, del rol del estudiante y del sector de producción de la localidad como potencial campo de trabajo. En ello se destaca el valor y el lugar que ocupa la escuela técnica en la localidad y su oferta formativa de calidad por tener docentes capacitados y especializados, y por contar con importantes recursos materiales innovadores y de avanzada tecnología (lo que se evidencia en el espacio y taller para las prácticas profesionalizantes), para la formación del técnico en industrialización de la madera y el mueble. Estos efectos formativos en los jóvenes estudiantes a su egreso, muchas veces no es percibido y valorado precisamente en estos términos, construyendo a partir de lo expuesto, miradas con rasgos positivos y otras con características negativas hacia el colectivo juvenil que asiste a la escuela. A su vez, según la mirada de los docentes y directivo, aquel beneficio de la formación, 
tiende a no ser reconocida por los empleadores del sector de la madera, los cuales tienen una falta de interés de incorporar mano de obra calificada, jóvenes operarios y/o técnicos con una formación profesional específica por parte del sector de producción.

Desde el abordaje de la mirada que tienen los empleadores de pequeñas y medianas empresas (pymes) acerca de la formación para el trabajo y los jóvenes, se identifican discursos referidos a que la formación brindada por la escuela técnica no es suficiente, lo que conlleva a éstos a continuar formando y capacitando a los jóvenes que eventualmente se incorporen a las empresas. Consideran como causas de esa deficitaria formación: clases más teóricas que prácticas, el oficio de la industria maderera se aprende, "observando" y "haciendo", las máquinas con las que cuenta el taller de carpintería de la escuela son de alta tecnología, lo que no concuerda y responde a la realidad de la industria local.

Si bien algunos empleadores reconocen que la escuela proporcionaría cierta formación de calidad, parecería recaer en la responsabilidad de cada estudiante si capitaliza o no esa formación, construyendo de esta manera -al igual que los actores de la institución educativa- imágenes (con rasgos negativos y positivos) de los jóvenes y de su relación con las actividades específicas del sector.

A partir de las perspectivas que tienen los actores de ambos sectores, se aprecia cómo se hace recaer la responsabilización de las dificultades de inserción laboral de los jóvenes en el sector contrario. Esto es que la escuela "critica" a los potenciales empleadores $y$, de parte de estos últimos, se minimiza lo que brinda la escuela en términos de formación para los jóvenes

Ahora bien, desde la perspectiva de los jóvenes estudiantes, los sentidos respecto a la formación que reciben, están construidos en función de sus experiencias educativas, laborales, y por sus expectativas futuras. De la experiencia educativa, mencionan que la elección de la oferta educativa se presenta por una exigencia familiar, por ser considerada una única opción que les brindaría la posibilidad de estudiar (al funcionar en el turno nocturno), y una próxima inserción laboral. En cuanto a la edad de los estudiantes, no es la esperada en relación al nivel de curso, evidenciándose así el fenómeno de la sobreedad. Sus trayectorias son diversas, por ser interrumpidas -ya sea por abandono y repitencia- asociadas a motivos como: problemas familiares, personales, paternidad/maternidad, por trabajo, por no querer estudiar y tener problemas con sus profesores, falta de ganas y/o "por vagar", por haber quedado "libre" en las materias, porque el turno nocturno de la escuela técnica es agotador y durante el día trabajan.

Los jóvenes estudiantes y sus familias pertenecen a un sector social de bajos recursos económicos y bajo nivel educativo. Algunos de los familiares se dedican al rubro del trabajo con la madera.

En lo que respecta a sus experiencias laborales, refieren tener experiencia previa -en el mercado informal- con contrataciones temporales y bajas remuneraciones. Las actividades mencionadas son: terminación de muebles, ayudante de pintura, albañilería, empleada doméstica, niñera, atención en la barra de un lugar bailable, ante la necesidad de generar ingresos económicos. En estos trabajos, se observa una escasa correspondencia con la formación recibida en la escuela técnica y más bien una relación con el perfil laboral de su familia, en tanto ejercen ocupaciones como: ama de casa y empleada doméstica, jornaleros en carpinterías, ayudantes de albañilería, dueños de pequeñas carpinterías y kioskos. 
Por su parte, sus expectativas futuras incluyen opciones como estudiar y al mismo tiempo trabajar, solo estudiar o solo el trabajo. En aquellos estudiantes que manifiestan continuar con estudios, se identifican carreras referidas a profesorados en diferentes áreas, la fuerza de seguridad, y tecnicaturas, dándose cuenta en la mayoría de los casos la escasa correspondencia entre la formación recibida y lo que proyectan a futuro, solo un caso se vincula con la formación que reciben, que se manifiesta en el continuar la tecnicatura de Seguridad e Higiene.

Con respecto a las conclusiones, se constata la existencia de diversos sentidos acerca de la formación para el trabajo, según los actores considerados. Lo llamativo es que las diferentes perspectivas no siempre coinciden e incluso van por carriles diferentes. Esto pone en evidencia la necesidad de establecer "puentes" o puntos de encuentros entre actores e instituciones que ayude a un reconocimiento del otro y sus expectativas y posibilidades.

Los núcleos problemáticos que existen en esta compleja trama entre el sistema educativo y el mercado laboral -como se fue señalando- afecta al colectivo juvenil de modo diferencial, en tanto que los jóvenes realizan diferentes recorridos que se traducen en trayectorias múltiples y variadas. Trayectorias que se van construyendo en el interjuego entre las condiciones posibles dentro de las estructuras sociales de las que forman parte (contexto familiar, social y económico) y por las decisiones personales y las expectativas a futuro que asumen. 